\title{
Correction to: Economy Doesn't Buy Community Wellbeing: a Study of Factors Shaping Community Wellbeing in South Korea
}

\author{
Seung Jong Lee ${ }^{1} \cdot$ Yunji Kim $^{2}$ \\ Published online: 1 July 2019 \\ (C) Springer Nature Switzerland AG 2019
}

\section{Correction to: International Journal of Community Well-Being https://doi.org/10.1007/s42413-018-0004-2}

Acknowledgements This paper was supported by the Ministry of Education of the Republic of Korea and the National Research Foundation of Korea (NRF-2016S1A3A2924563).

Publisher's Note Springer Nature remains neutral with regard to jurisdictional claims in published maps and institutional affiliations.

The online version of the original article can be found at https://doi.org/10.1007/s42413-018-0004-2

\author{
Seung Jong Lee \\ slee@snu.ac.kr \\ Yunji Kim \\ ykim535@wisc.edu
}

1 Graduate School of Public Administration, Seoul National University, GSPA Building 57-1 Room 310, Seoul 135969, South Korea

2 Department of Planning and Landscape Architecture, University of Wisconsin-Madison, 204 Music Hall, 925 Bascom Mall, Madison, WI 53706, USA 